Research Article

\title{
Inverse System Analysis and Modeling of Bearingless Induction Motor and Its Combined Control Strategy
}

\author{
Wen-shao Bu, Cong-lin Zu, and Chun-xiao Lu \\ Department of Automation, College of Information Engineering, Henan University of Science and Technology, Luoyang 471023, China \\ Correspondence should be addressed to Wen-shao Bu; wsbu@haust.edu.cn
}

Received 24 March 2014; Revised 3 August 2014; Accepted 11 August 2014; Published 30 November 2014

Academic Editor: Hung-Yuan Chung

Copyright ( 2014 Wen-shao Bu et al. This is an open access article distributed under the Creative Commons Attribution License, which permits unrestricted use, distribution, and reproduction in any medium, provided the original work is properly cited.

\begin{abstract}
Bearingless induction motor is a multi-variable, nonlinear and strong coupling object, the existing inverse control method ignores the stator current dynamics of torque system. Aiming at its nonlinear and strong coupling problems, a novel combinatorial decoupling control strategy based on stator flux orientation and inverse system method is proposed. Taking the stator current dynamics of four-pole torque system into account, the reversibility and inverse system model of torque system are analyzed and established. Adopting the inverse system method, the dynamic decoupling between motor speed and stator flux-linkage is achieved; by online identification and calculation, the airgap flux-linkage of torque system is got. Based on above, feedback and compensation control of two radial displacement components of two-pole suspension system is realized. Simulation results have shown the higher decoupling control performance and stronger anti-interference ability of the decoupling control system; the proposed decoupling strategy not only owns the characteristics of be simple and convenient, but also is effective and feasible.
\end{abstract}

\section{Introduction}

Although conventional motor with mechanical bearing has been widely used in the field of industrial production [1$4]$, it cannot meet the need of long time high-speed operation. Then motor with magnetic bearings is developed and widely used in high-speed drive kingdoms [5-7], but it still has a series of disadvantages [8-11], such as higher magnetic suspensions cost and difficulty to overspeed. Based on the comparability of stator structure between magnetic bearing and conventional AC motor, the bearingless motor is proposed [12-15]. Bearingless motor is a new type of electrical machinery that is suitable for long time and highspeed operation [16, 17]. In bearingless motor, there are two sets of windings, including torque wingding, that is, conventional motor winding, and suspension control winding. Under certain conditions, through the interaction of air gap magnetic fields generated by the two sets of winding, stable and controllable radial electromagnetic force can be produced [8]. The controllable electromagnetic force is called magnetic suspension force and can be used for the reliable suspension control of bearingless rotor. Compared with the motor with magnetic bearings, bearingless motor owns a series of advantages, such as shorter rotor shaft and higher critical speed, and then it is more suitable for the long time and high-speed running. Now, urgent needs for bearingless control technology of motor have been proposed in the kingdoms of sealed transmission, aerospace, and advanced manufacturing $[10,13,16]$. Bearingless control technology can be used with all kinds of AC motors [8]. In many types of bearingless motor, bearingless induction motor not only owns the merits of no lubrication and no mechanical friction and noise, but also owns robust mechanical structure and then has broad application prospect.

In bearingless induction motor, there exist complex electromagnetic coupling relations [8]. To achieve its high performance control, it is necessary to achieve dynamic decoupling between relevant variables. Aiming at the complex nonlinear system, inverse system method is a direct feedback linearization method that is proposed in recent years. Based on the inverse system method, the decoupling control between motor speed, rotor flux-linkage and two radial displacement components are achieved in [18]. But the flux-linkage of torque system is not orientated, the established 
mathematical model is complex, and the presented method is difficult for application. To avoid the complex mathematical model of bearingless induction motor, neural network inverse control method is researched in $[19,20]$. To simplify the mathematical model of bearingless induction motor, rotor flux orientation and inverse system method have been adopted in [21]; the decoupling control problem between relevant variables was researched. In the existing references, the rotor flux-linkage is used as controlled variable, but, from the motion control theory of induction motor, the estimation precision of rotor flux-linkage is influenced inevitably by the rotor parameters. At the same time, the dynamic differential equations of stator current are ignored in existing references, and then the dynamic decoupling control performance of bearingless induction motor would be affected inevitably in long time operation. Compared with the rotor flux-linkage, the stator flux-linkage can avoid the influence of rotor parameters naturally, and the estimation precision of stator flux-linkage only relies on the stator resistance and has the characteristics of being robust and being easy to realize [22]. But up to now, with regard to the inverse system decoupling control method of bearingless induction motor based on stator flux orientation, there are no study reports.

The control precision of torque system directly influences the control performance of suspension system. To achieve the decoupling control of bearingless induction motor with high performance, the four-pole bearingless induction motor with two-pole suspension control windings is regarded as the object in this paper; a novel combined control strategy based on inverse system method is researched and proposed. To avoid the influence of rotor parameters, the stator flux orientation is adopted; under the conditions of taking the dynamic differential equations of stator current into account and based on inverse system method, the torque system is dynamically decoupled into two linear subsystems, that is, motor speed subsystem and stator flux-linkage subsystem. After that, feedback and compensation control of radial displacement are achieved in suspension control system. Simulation results have shown the effectiveness and feasibility of the proposed control strategy.

\section{Mathematical Model of Bearingless Induction Motor}

2.1. Working Principle of Bearingless Motor. From the electromagnetic theory, there exists a Maxwell electromagnetic force on the interface between iron core and air gap; the Maxwell force is approximately vertical to the interface. If the air gap flux density is distributed symmetrically along the rotor surface, the resultant force would be equal to zero. The rotor's eccentricity from the stator's center will lead to the asymmetrical distribution of the air gap flux density and, as a result, the resultant force will not be equal to zero again, and the resultant radial force is called unilateral magnetic pull. To achieve stable suspension of the bearingless rotor, it is necessary to produce a controlled radial force to overcome the unilateral magnetic pull and the external load in the radial direction.

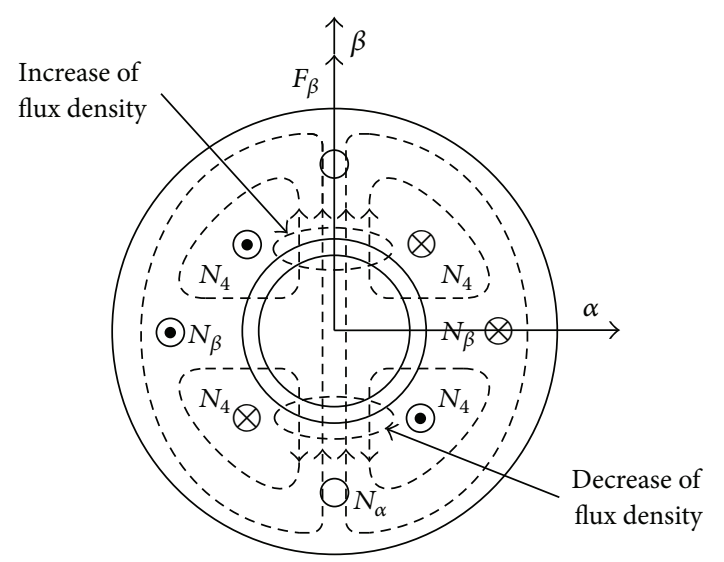

FIGURE 1: Sketch map of magnetic suspension force's production of bearingless motor.

There are two sets of windings in the stator slots of bearingless motor, which include torque windings and suspension windings. When AC current is injected into the torque windings, the produced rotating magnetic field is used to control the motor speed, and when AC current is injected into the suspension windings, the produced rotating magnetic field is used to control the suspension of bearingless rotor. The produced magnetic field by suspension windings is called suspension control magnetic field. The superposition of suspension control magnetic filed on the conventional motor magnetic field would lead to the enhancement of airgap magnetic field in some air gap region, and the air-gap magnetic field in some other air gap region would be weaken. As the result, radial electromagnetic force that acts on the rotor will come into being. Assuming that the number of pole pairs of torque windings is $p_{1}$ and the electrical angle frequency of injected current is $\omega_{1}$, the number of pole pairs of suspension control windings is $p_{2}$ and the electrical angle frequency of injected current is $\omega_{2}$. When their numbers of pole pairs and the electrical angle frequencies meet the qualification of " $p_{2}=p_{1} \pm 1, \omega_{1}=\omega_{2}$," the amplitude and direction of the produced radial electromagnetic force can be stably controlled [8]. The controllable radial electromagnetic force is called magnetic suspension force and can be used to overcome the inner unilateral magnetic pull and external radial load and to achieve the stable suspension of bearingless rotor. This is the magnetic suspension principle of bearingless motor.

Figure 1 shows the sketch map of magnetic suspension force's production principle of bearingless motor. When fourpole torque windings and two-pole suspension windings are injected currents, as Figure 1, the radial magnetic suspension force along $\beta$ direction is produced. If the current direction of suspension windings is reversed, the radial magnetic suspension force would be produced along the opposite $\beta$ direction. The production principle of magnetic suspension force along $\alpha$ direction is similar.

2.2. Mathematical Model of Torque System Based on Stator Flux Orientation. The production principle of 
electromagnetic torque of bearingless induction motor is similar to that of conventional motor. To avoid the influence of rotor parameters on the estimation accuracy of motor flux-linkage, the stator flux orientation strategy will be adopted here.

Defining $d q$ as the synchronous reference frame oriented by four-pole torque system, ignoring the influence of two-pole suspension control magnetic field on four-pole motor magnetic field, taking the stator current dynamic into account, and considering the constraint conditions of stator flux orientation, that is, " $\psi_{s 1}=\psi_{s 1 d}, \psi_{s 1 q}=\dot{\psi}_{s 1 q}=0$," the model of torque system can be derived as follows:

$$
\begin{gathered}
\frac{d i_{s 1 d}}{d t}=-\gamma \xi i_{s 1 d}+\left(\frac{u_{s 1 q}-R_{s} i_{s 1 q}}{\psi_{s 1}}-\omega\right) i_{s 1 q}+\xi \tau_{r} \psi_{s 1}+\xi u_{s 1 d} \\
\frac{d i_{s 1 q}}{d t}=-\gamma \xi i_{s 1 q}-\left(\frac{u_{s 1 q}-R_{s} i_{s 1 q}}{\psi_{s 1}}-\omega\right) i_{s 1 d}-\xi \omega \psi_{s 1}+\xi u_{s 1 q}, \\
\frac{d \psi_{s 1}}{d t}=-R_{s} i_{s 1 d}+u_{s 1 d} \\
\frac{d \omega}{d t}=\frac{p_{1}^{2}}{J} i_{s 1 q} \psi_{s 1}-\frac{p_{1}}{J} T
\end{gathered}
$$

In (1)-(4),

$$
\gamma=\frac{R_{s} L_{r 1}+R_{r} L_{s 1}}{L_{r 1}}, \quad \xi=\frac{1}{\sigma L_{s 1}}, \quad \tau_{r}=\frac{R_{r}}{L_{r 1}} .
$$

And the synchronous angular frequency $\omega_{1}$ can be expressed as follows:

$$
\omega_{1}=\frac{u_{s 1 q}-R_{s} i_{s 1 q}}{\psi_{s 1}} .
$$

In (1)-(6), $i_{s 1 d}$ and $i_{s 1 q}$ are the stator current components of torque windings along $d$ and $q$ reference axis; $\psi_{s 1}$ is the stator flux-linkage of torque system; $\omega$ is the rotational angular velocity of rotor; $L_{m 1}$ is the mutual inductance of equivalent two-phase torque winding in $d q$ reference axis; $L_{s 1}$ is the self-inductance of equivalent two-phase torque winding in $d q$ reference axis, $L_{s 1}=L_{m 1}+L_{s 1 l}$; $L_{r 1}$ is the self-inductance of equivalent two-phase rotor winding in $d q$ reference axis, $L_{r 1}=L_{m 1}+L_{r 1 l} ; L_{s 1 l}$ and $L_{r 1 l}$ are the leakage inductances of stator windings and rotor windings of torque system in $d q$ reference frame; $R_{r}$ is the rotor resistance; $T_{L}$ is the load torque.

From (1) and (2), there exists coupling between two stator current components.

\subsection{Mathematical Model of Magnetic Suspension System.} In normal operation of bearingless induction motor, the eccentricity of rotor is very small, and the magnetic field intensity of suspension system is far smaller than that of torque system. Then, the influence of suspension magnetic field on the magnetic field distribution of torque system can be ignored [8]. Then, according to the operation principle of bearingless induction, the controllable magnetic suspension force components along $\alpha$ and $\beta$ directions can be derived as follows:

$$
\begin{aligned}
& F_{\alpha}=K_{m}\left(i_{s 2 d} \psi_{1 d}+i_{s 2 q} \psi_{1 q}\right), \\
& F_{\beta}=K_{m}\left(i_{s 2 d} \psi_{1 q}-i_{s 2 q} \psi_{1 d}\right) .
\end{aligned}
$$

In (7), $F_{\alpha}$ and $F_{\beta}$ are controllable suspension force components along $\alpha$ and $\beta$ directions; $\psi_{1 d}$ and $\psi_{1 q}$ are air gap flux-linkage components of torque system along $d$ and $q$ reference axes; $i_{s 2 d}$ and $i_{s 2 q}$ are suspension control current components along $d$ and $q$ reference axes; $K_{m}$ is magnetic suspension force coefficient determined by the configuration of bearingless induction motor. $K_{m}$ can be expressed as follows [23]:

$$
K_{m}=\frac{\pi L_{m 2}}{4 \mu_{0} l r W_{1} W_{2}} .
$$

In (8), $L_{m 2}$ is the single-phase excited inductance of threephase symmetrical suspension winding; $\mu_{0}$ is the magnetic permeability of air; $l$ is the length of stator iron core; $r$ is the interior radius of stator; $W_{1}$ and $W_{2}$ are the numbers of turns in series per phase of three-phase concentrated fullpitch torque windings and three-phase concentrated fullpitch suspension control windings.

When the rotor deviates from stator's center, through the analysis of Maxwell force, the unilateral magnetic pull components along $\alpha$ and $\beta$ directions can be derived as follows:

$$
f_{\alpha}=k_{s} \alpha, \quad f_{\beta}=k_{s} \beta .
$$

In (9), $k_{s}$ is the radial displacement stiffness coefficient determined by the configuration and the magnetic field intensity of bearingless induction motor. For three-phase bearingless induction motor, $k_{s}$ can be derived as follows:

$$
k_{s}=\frac{\pi r l B_{1 m}^{2}}{2 \mu_{0} \delta_{0}}=\frac{\pi \psi_{1 m}^{2}}{3 \mu_{0} r l W_{1}^{2} \delta_{0}}=\frac{\pi\left(\psi_{1 d}^{2}+\psi_{1 q}^{2}\right)}{3 \mu_{0} r l W_{1}^{2} \delta_{0}} .
$$

In (10), $B_{1 m}$ is the amplitude of air gap magnetic flux density of four-pole torque system; $\delta_{0}$ is the average air gap length of bearingless induction motor.

According to the principles of mechanical dynamics, the suspension motion equations of bearingless rotor in $\alpha$ and $\beta$ directions can be expressed as follows:

$$
m \ddot{\alpha}=F_{\alpha}-f_{\alpha}, \quad m \ddot{\beta}=F_{\beta}-f_{\beta},
$$

where $m$ is the rotor mass.

\section{Dynamic Decoupling Control Strategy of Bearingless Induction Motor}

The controllable magnetic suspension force of bearingless motor is the result of the magnetic coupling between torque system and suspension system. The flux-linkage control precisions of torque system and the dynamic decoupling 
performance between speed and flux-linkage subsystems, undoubtedly, have an impact on the magnetic suspension control performance of bearingless induction motor.

To realize the flux-linkage's linearization control of torque system, so as to improve the decoupling control performance of magnetic suspension system, a combined control strategy is proposed. Hereinto, the torque system based on stator flux orientation will be decoupled by inverse system method; based on the above, the feedback and compensation control of suspension system will be carried out.

3.1. Inverse System Modeling of Torque System Based on Stator Flux Orientation. To take the stator current differential equation of torque system into account, the stator voltage components of torque system are selected as the input variable.

Selecting the input variables,

$$
u=\left(u_{1}, u_{2}\right)^{T}=\left(u_{s 1 d}, u_{s 1 q}\right)^{T} .
$$

Selecting the state variables,

$$
x=\left(x_{1}, x_{2}, x_{3}, x_{4}\right)^{T}=\left(i_{s 1 d}, i_{s 1 q}, \psi_{s 1}, \omega\right)^{T} .
$$

Selecting the output variables,

$$
y=\left(y_{1}, y_{2}\right)^{T}=\left(\psi_{s 1}, \omega\right)^{T} .
$$

Putting (12)-(14) into (1)-(4), the state equations of torque system based on stator flux orientation can be derived as follows:

$$
\begin{gathered}
\dot{x}_{1}=-\gamma \xi x_{1}+\left(\frac{u_{2}-R_{s} x_{2}}{x_{3}}-x_{4}\right) x_{2}+\xi \tau_{r} x_{3}+\xi u_{1}, \\
\dot{x}_{2}=-\gamma \xi x_{2}-\left(\frac{u_{2}-R_{s} x_{2}}{x_{3}}-x_{4}\right) x_{1}-\xi x_{3} x_{4}+\xi u_{2}, \\
\dot{x}_{3}=-R_{s} x_{1}+u_{1}, \\
\dot{x}_{4}=\frac{p_{1}^{2}}{J} x_{2} x_{3}-\frac{p_{1}}{J} T_{L} .
\end{gathered}
$$

Equations (15) and (16) are the dynamic equations of stator current; there exists an obvious cross-coupling between them.

By means of interactor algorithm, the reversibility of torque system can be analyzed. The output variables $Y=$ $\left(y_{1}, y_{2}\right)^{T}$ should be asked the derivative to time gradually, until the input variable $u_{j}(j=1,2)$ is obviously included in the derivative functions of each $y_{i}(i=1,2)$. The detailed solving steps are as follows:

$$
\begin{aligned}
& \dot{y}_{1}=\dot{x}_{3}=-R_{s} x_{1}+u_{1}, \\
& \dot{y}_{2}=\frac{p_{1}^{2}}{J} x_{2} x_{3}-\frac{p_{1}}{J} T_{L},
\end{aligned}
$$

$\ddot{y}_{2}$

$$
=\frac{p_{1}^{2}\left[-\gamma \xi x_{2} x_{3}-\xi x_{3}^{2} x_{4}+x_{1} x_{3} x_{4}+x_{2} u_{1}+\left(\xi x_{3}-x_{1}\right) u_{2}\right]}{J} .
$$

Assumption 1. Vector $Y$ is as follows:

$$
Y=\left(\dot{y}_{1}, \ddot{y}_{2}\right)^{T} .
$$

From (19) to (20), the Jacobi matrix of torque system can be derived as follows:

$$
A(x, u)=\frac{\partial Y}{\partial u^{T}}=\left[\begin{array}{cc}
1 & 0 \\
\frac{p_{1}^{2}}{J} x_{2} & \frac{p_{1}^{2}}{J}\left(\xi x_{3}-x_{1}\right)
\end{array}\right] .
$$

According to (21), if " $\xi x_{3}-x_{1} \neq 0$ " is satisfied, "det $[A(x, u)] \neq 0$ " will also be satisfied. Then the Jacobi matrix $A(x, u)$ is nonsingular.

The rotor flux-linkage of four-pole torque system can be expressed as (22)

$$
\psi_{r 1 d}=\left(\psi_{s 1}-\sigma L_{s 1} i_{s 1 d}\right) \frac{L_{r 1}}{L_{m 1}}=\left(\xi x_{3}-x_{1}\right) \frac{L_{r 1}}{\xi L_{m 1}} .
$$

As the rotor flux-linkage is not equal to zero in the normal operation of bearingless induction motor, then " $\xi x_{7}-x_{5} \neq 0$ " is true and the Jacobi matrix $A(x, u)$ is nonsingular.

The relative order is $\alpha=\left(\alpha_{1}, \alpha_{2}\right)=(1,2)$; the sum of $\alpha_{i}(i=1,2)$ is equal to 3 and is smaller than the order of state equations. Then according to the reverse system theory, the torque system based on stator flux orientation is reversible.

Selecting the input variables of inverse system,

$$
v=\left(\nu_{1}, v_{2}\right)^{T}=\left(\dot{y}_{1}, \ddot{y}_{2}\right)^{T}=Y .
$$

According to the implicit function theorem, the inverse system of torque system based on stator flux orientation can be expressed as the format in (24)

$$
u=\phi\left(x, v_{1}, v_{2}\right)
$$

Putting (19) into (23), the inverse system mathematical model of torque system based on stator flux orientation can be derived as follows:

$$
u_{1}=v_{1}+R_{s} x_{1}
$$

$$
\begin{aligned}
& u_{2} \\
& =\frac{1}{\left(\xi x_{3}-x_{1}\right)} \\
& \quad \times\left[\frac{J}{p_{1}^{2}} \nu_{2}+\gamma \xi x_{2} x_{3}+\xi x_{3}^{2} x_{4}-x_{1} x_{3} x_{4}-x_{6}\left(\nu_{1}+R_{s} x_{1}\right)\right] .
\end{aligned}
$$

3.2. Inverse System Decoupling Control Strategy of Torque System Based on Stator Flux Orientation. Under the conditions of considering the stator current dynamics, the inverse system model of torque system based on stator flux orientation has been derived in upper section. By series connecting the inverse system expressed by (25) in front of the original torque system, then the torque system can be compensated to a linear system with two linear subsystems, which include a first-order linear integral stator flux-linkage subsystem and a 


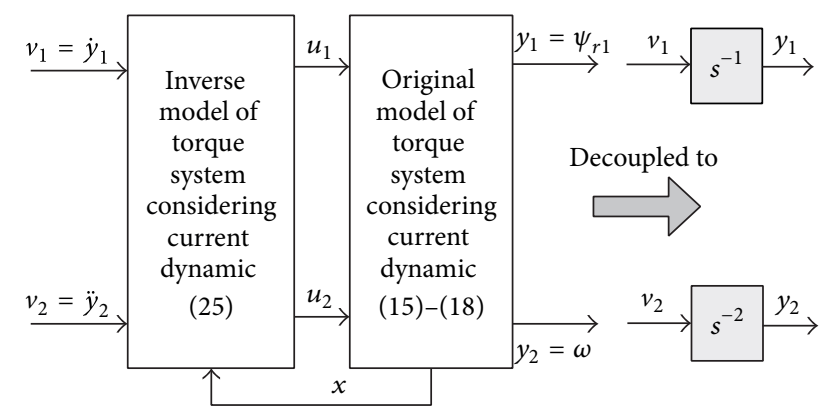

Figure 2: Inverse system decoupling of torque system based on stator flux orientation.

second-order linear integral speed subsystem. Figure 2 shows the inverse system decoupling principle diagram of torque system; the decoupled two linear subsystems are controlled separately by $v_{1}$ and $v_{2}$.

In practical application, under the influence of various factors, the two subsystems are not ideal linear subsystems. Then, aiming at each decoupled linear subsystem, the additional closed-loop controller should be designed to improve the dynamic and static control performance. The decoupled stator flux-linkage subsystem is a first-order linear integral subsystem and a PI controller is adopted. The decoupled speed subsystem is a second-order linear integral subsystem and then a lead compensation controller is adopted.

For torque system, when the proposed decoupling control strategy is adopted, there are the following obvious advantages.

(1) After considering the stator current dynamics, by way of inverse system method, the cross-coupling between the two stator current components of torque system in $d q$ reference frame can be eliminated naturally; at the same time the output of inverse system is voltage variable. Then, in the original torque system, the current close-loop can be omitted; that is, the current tracking PWM inverter can be replaced by conventional SPWM inverter and then the control system of bearingless induction motor can be simplified to a certain extent.

(2) After considering the stator current dynamics, load torque variable no longer exists in the mathematical model of inverse system and then the identification and calculation of load torque is unnecessary in the implementation of inverse system. And then the control system of bearingless induction motor can be further simplified.

(3) For the stator flux orientation adopted by torque system, the influence of rotor parameters on the estimation precision of motor flux-linkage can be avoided naturally.

3.3. Feedback and Compensation Control of Suspension System. Comparing the given signals of radial displacement $\alpha^{*}$ and $\beta^{*}$ with the measured values $\alpha$ and $\beta$, by PID negative feedback close-loop regulation and by compensation of unilateral magnetic pull, the given signals of magnetic suspension force $F_{\alpha}^{*}$ and $F_{\beta}^{*}$ can be derived. Then, according to the mathematical model of magnetic suspension force in (7), the suspension control current signal can be derived. But the air gap flux-linkage of torque system is required.

According to the stator flux-linkage model of torque system in $\alpha \beta$ reference frame,

$$
\begin{aligned}
& \psi_{s 1 \alpha}=\int\left(u_{s 1 \alpha}-R_{s} i_{s 1 \alpha}\right) d t, \\
& \psi_{s 1 \beta}=\int\left(u_{s 1 \beta}-R_{s} i_{s 1 \beta}\right) d t .
\end{aligned}
$$

The amplitude $\psi_{s 1}$ and space position angle $\varphi$ of stator flux-linkage can be derived as follows:

$$
\begin{gathered}
\psi_{s 1}=\sqrt{\psi_{s 1 \alpha}^{2}+\psi_{s 1 \beta}^{2}}, \\
\sin \varphi=\frac{\psi_{s 1 \beta}}{\psi_{s 1}}, \quad \cos \varphi=\frac{\psi_{s 1 \alpha}}{\psi_{s 1}} .
\end{gathered}
$$

As there is no rotor parameter in the model of stator fluxlinkage, the influence of rotor parameters on the identification precision of motor flux-linkage is avoided undoubtedly. The stator flux-linkage mode presented in (26)-(27) belongs to voltage model and there exists an integral part. But the bearingless motor always works on higher speed, so the produced error by integral part can be ignored. The following air gap flux-linkage components of torque system along $d$ and $q$ reference axes can be identified online as follows:

$$
\begin{gathered}
\psi_{1 d}=\psi_{s 1}-L_{s 1} i_{s 1 d}=x_{3}-L_{s 1} x_{1}, \\
\psi_{1 q}=-L_{s 1} i_{s 1 q}=-L_{s 1} x_{2} .
\end{gathered}
$$

According to the given signals of magnetic suspension force and the air gap flux-linkage of torque system, the following given signals of suspension control current, that is, $i_{s 2 d}^{*}$ and $i_{s 2 q}^{*}$, can be derived as follows:

$$
\left(\begin{array}{c}
i_{s 2 d}^{*} \\
i_{s 2 q}^{*}
\end{array}\right)=\frac{1}{K_{m}\left(\psi_{1 d}^{2}+\psi_{1 q}^{2}\right)}\left(\begin{array}{cc}
\psi_{1 d} & \psi_{1 q} \\
\psi_{1 q} & -\psi_{1 d}
\end{array}\right)\left(\begin{array}{c}
F_{\alpha}^{*} \\
F_{\beta}^{*}
\end{array}\right) .
$$

After comparing the given signals of suspension control current with relevant measured signals, respectively, and by close-loop feedback control, the decoupling control voltage signals of suspension windings along $d$ and $q$ reference axes, that is, $u_{s 2 d}^{*}$ and $u_{s 2 q}^{*}$, can be derived, respectively.

Figure 3 is the schematic diagram of the decoupling control system of bearingless induction motor.

\section{System Simulation Validation and Analysis}

To verify the validity of the estimated model and the proposed decoupling control strategy, aiming at four-pole bearingless induction prototype motor with two-pole suspension windings, and according to the control system shown in Figure 3, the system simulation research has been made by Matlab/Simulink. The parameters of bearingless induction prototype motor are given in Table 1. 


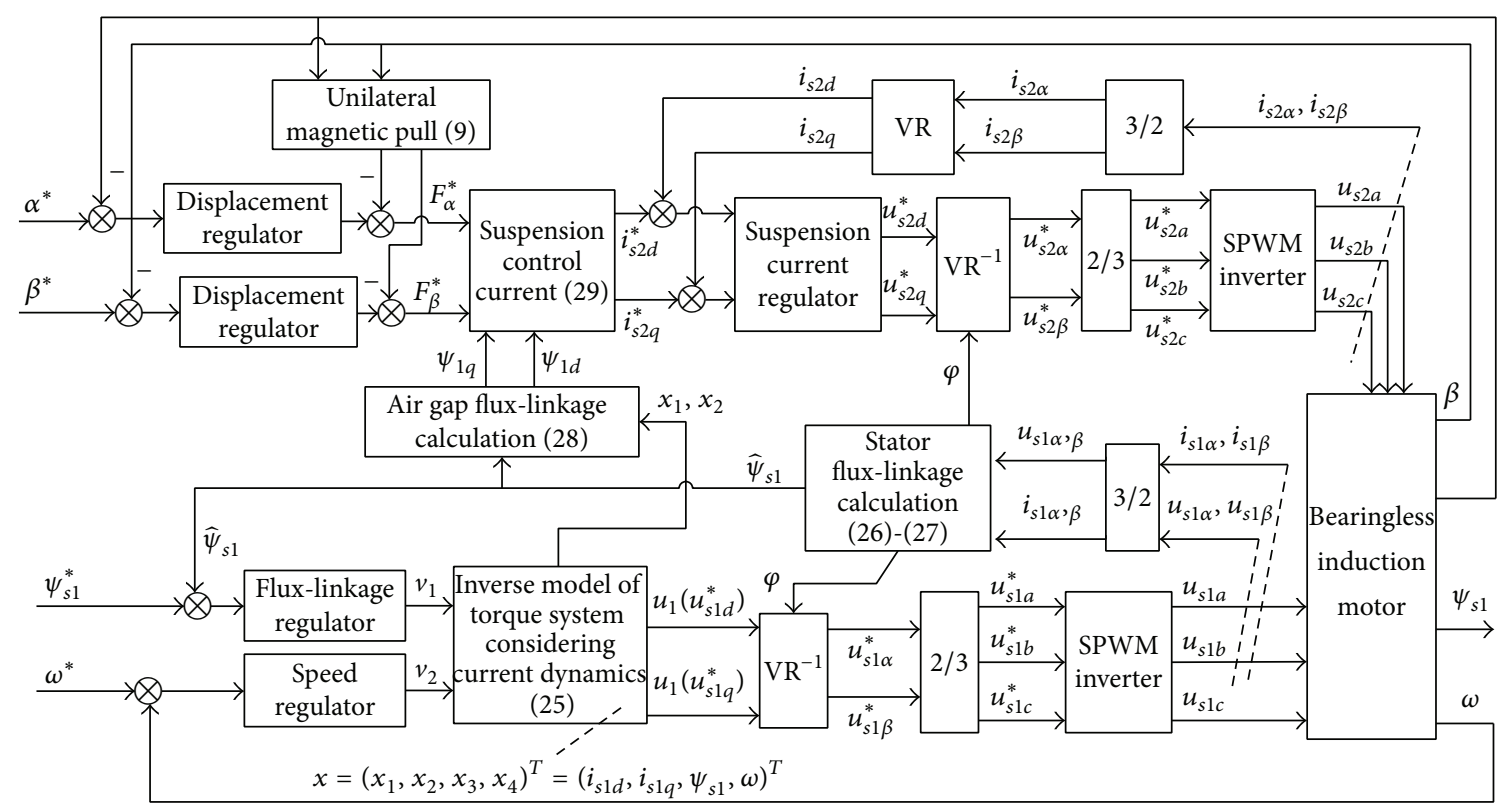

FIgURE 3: Schematic diagram of the decoupling control system of bearingless induction motor.

TABLE 1: Parameters of bearingless induction prototype motor.

\begin{tabular}{llc}
\hline Parameters & Description & Value \\
\hline$r$ & Stator inner diameter $(\mathrm{mm})$ & 62 \\
$l$ & Effective core length $(\mathrm{mm})$ & 82 \\
$\delta_{1}$ & Air gap of auxiliary bearing $(\mathrm{mm})$ & 0.2 \\
$P$ & Power of motor $(\mathrm{kW})$ & 2.2 \\
$R_{s}$ & Stator winding resistance $(\Omega)$ & 1.6 \\
$R_{r}$ & Rotor winding resistance $(\Omega)$ & 1.423 \\
$L_{s 1 l}$ & Leakage inductance of torque windings $(\mathrm{H})$ & 0.0043 \\
$L_{r 1 l}$ & Leakage inductance of rotor windings of & 0.0043 \\
$L_{m 1}$ & torque system (H) & 0.0859 \\
$J$ & Mutual inductance of torque system $(\mathrm{H})$ & 0.024 \\
$R_{s 2}$ & Rotation inertia of motor $\left(\mathrm{kg} \cdot \mathrm{m}^{2}\right)$ & 2.7 \\
$L_{s 2 l}$ & Suspension stator winding resistance & 0.00398 \\
$L_{m 2}$ & Leakage inductance of suspension stator & 0.230 \\
\hline
\end{tabular}

4.1. Simulation Conditions. Initial radial displacement is $\alpha_{0}=$ $-0.12 \mathrm{~mm}, \beta_{0}=-0.16 \mathrm{~mm}$; initial given value of rotational speed is $n^{*}=1500 \mathrm{r} / \mathrm{min}$; initial value of stator flux-linkage is $\psi_{s 1}^{*}=0.95 \mathrm{~Wb}$; initial given value of radial displacements is $\alpha^{*}=\beta^{*}=0$; the motor starts with no-load. To verify the validity of the proposed control strategy, the given signals of system will be suddenly changed at different moments.

Figure 4 shows the simulation response curves of decoupling control system. Hereinto, Figure 4(a) shows the speed response curve; Figure 4(b) shows the stator flux-linkage response curve; Figures 4(c) and 4(d) present the response curves of $\alpha$ and $\beta$ radial displacement components; and Figure 4(e) gives the curve of load torque.
From Figure 4, there are the following conclusions.

(1) When the bearingless induction motor starts with zero torque, the speed reaches its given value within $0.2 \mathrm{~s}$ and the overshoot does not exceed $8 \%$; the stator flux-linkage reaches its stable state within $0.1 \mathrm{~s}$ and after a short time adjustment $\alpha$ and $\beta$ radial displacement components reach their stable values within $0.2 \mathrm{~s}$ and their overshoots are all within $20 \mu \mathrm{m}$. Simulation results have shown that the presented control system owns the characteristics of fast starting and small overshoot; at the same time, the control system has higher static and dynamic control performance.

(2) When the stator flux-linkage changes suddenly to $0.45 \mathrm{~Wb}$, at $0.7 \mathrm{~s}$, the motor speed and two radial displacement components are not affected basically; when the motor speed changes suddenly to $3500 \mathrm{r} / \mathrm{min}$, at $1.2 \mathrm{~s}$, the stator flux-linkage and two radial displacement components are not affected basically also. Simulation results not only have shown the excellent dynamic decoupling control performance between motor speed and stator flux-linkage subsystems but also have shown the excellent dynamic decoupling control performance between torque system and suspension system.

(3) When $\alpha$ radial displacement component is suddenly changed to $0.05 \mathrm{~mm}$, at $2.2 \mathrm{~s}$, and is suddenly restored to $0.0 \mathrm{~mm}$, at $2.4 \mathrm{~s}, \beta$ radial displacement component almost has no change; when $\beta$ radial displacement component is suddenly changed to $-0.05 \mathrm{~mm}$, at $2.6 \mathrm{~s}$, and is suddenly restored to $0.0 \mathrm{~mm}$, at $2.8 \mathrm{~s}, \alpha$ radial displacement component almost has no change too. Simulation results have shown that excellent dynamic and static decoupling control performances have 


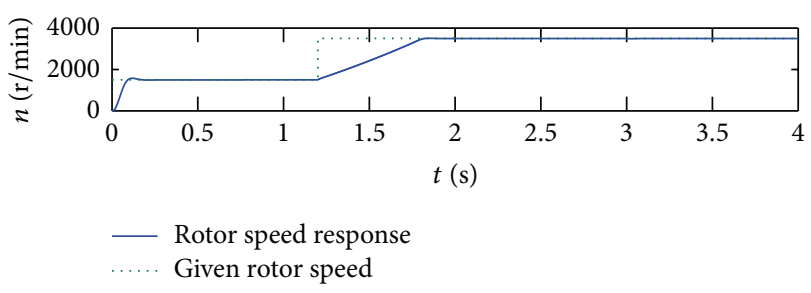

(a) Rotor speed

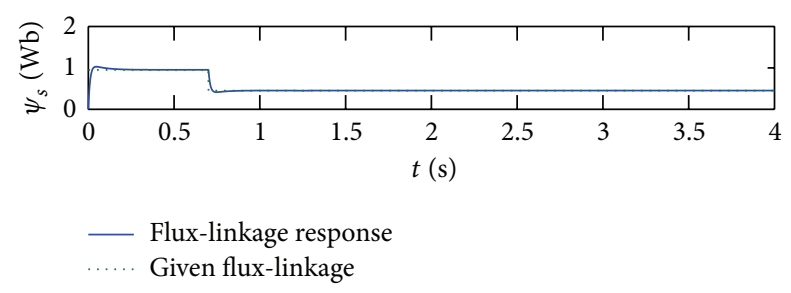

(b) Stator flux-linkage

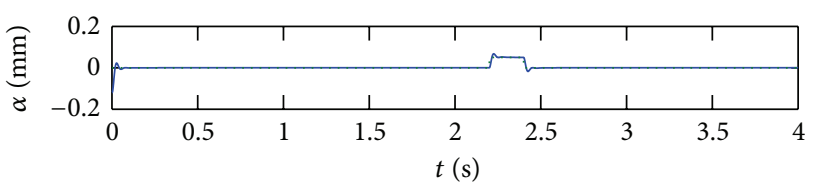

$\alpha$-direction displacement response

Given $\alpha$-direction displacement

(c) $\alpha$-direction radial displacement

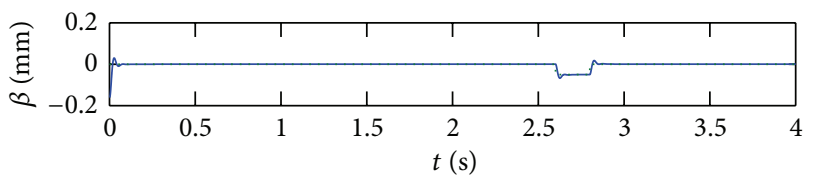

- $\beta$-direction displacement response Given $\beta$-direction displacement

(d) $\beta$-direction radial displacement

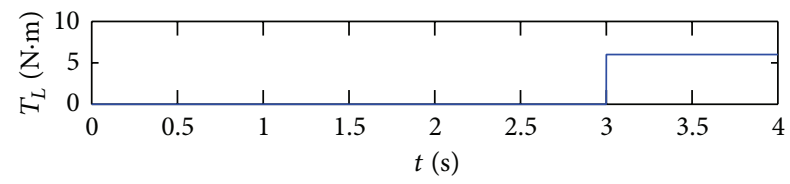

(e) Load torque

FIGURE 4: Response curves of decoupling control system.

been achieved between $\alpha$ and $\beta$ radial displacement components.

(4) In the change process of $\alpha$ and $\beta$ components, the motor speed and stator flux-linkage have no change, basically. Simulation results have shown excellent dynamic static decoupling control performances between suspension system and torque system in the further step.

(5) When 6.0 N.m load torque is added suddenly on the bearingless induction motor at $3.0 \mathrm{~s}$, the change of motor speed is very little and the stator fluxlinkage and two radial displacement components are almost unchanged. Simulation results have shown the excellent antidisturbance ability of the presented decoupling control system of bearingless induction motor; the cause of strong antiload disturbance ability is due to the fact that the dynamics of stator current components has been taking into account.

\section{Conclusion}

Bearingless induction motor is a multivariable, nonlinear, and strong coupling object. Aiming at the nonlinear strong coupling problem of bearingless induction motor, a convenient combined control strategy has been proposed.

The control precision of torque system will directly affect the control performance of suspension system. Then, to reduce the influence of rotor parameters, stator flux orientation is adopted instead of conventional rotor flux orientation; under the conditions of taking the stator current's dynamic differential equation of torque winding into account, the dynamic mathematical models of bearingless induction motor are established firstly; by way of interactor algorithm, the reversibility of torque system is analyzed and confirmed; according to the implicit function theorem, the inverse dynamic mathematical model of torque system is researched and established, and by way of inverse system method, the dynamic decoupling is achieved between motor speed and stator flux-linkage; for the convenience of control current calculation of suspension system, the air gap flux-linkage information of torque system is identified online. In suspension control system, the negative feedback close-loop control of radial displacement and the feed-forward compensation control of unilateral magnetic pull are adopted. At the end, system simulation analysis has been made.

From the simulation results, when adopting the proposed control strategy, there are the following conclusions.

(1) Not only the dynamic decoupling control between motor speed, stator flux-linkage, and two radial displacements can be achieved reliably.

(2) The influence of rotor parameters can be avoided effectively and the control precision of motor fluxlinkage can be ensured; based on above, favorable static and dynamic suspension control performance can be achieved; moreover, the system owns the characteristics of fast response speed, small overshoot, stronger antidisturbance ability, and so forth.

(3) Under the conditions of considering stator current's dynamics, by inverse system method, the crosscoupling between the two stator current components of torque system under $d q$ reference frame can be eliminated; then, in the original torque system, the current close-loop can be omitted naturally and the control system of bearingless induction motor can be simplified to a certain extent.

(4) Under the conditions of considering stator current's dynamics, torque variable in the model of inverse system no longer exists, and then the identification of load torque is unnecessary and the control system 
of bearingless induction motor can be further simplified.

On the other hand, although high dynamic and static control performance can be achieved by the proposed control strategy, the adopted regulators are conventional PID. Next, with the aid of various control theories, such as robust control, fuzzy adaptive control, and sliding mode control, new regulators with higher control performances will be studied. At the same time, the proposed control strategy is only verified by simulation; next step, new experimental equipment will be developed and experimental research will be made in near future.

\section{Conflict of Interests}

The authors declare that there is no conflict of interests regarding the publication of this paper.

\section{Acknowledgments}

The support of the Natural Science Foundation of China (51277053), the International Cooperation Project on Science and Technology of Henan province (114300510029), and the Nature Science Fund of Henan Province Education Bureau (2010B510011) is acknowledged.

\section{References}

[1] Y. H. Okazaki, M. Hagiwara, and H. Akagi, "A speed-sensorless start-up method of an induction motor driven by a modular multilevel cascade inverter (MMCI-DSCC)," IEEE Transactions on Industry Applications, vol. 50, no. 4, pp. 2671-2680, 2014.

[2] D. Y. Kim, G. H. Jang, and J. K. Nam, "Magnetically induced vibrations in an IPM motor due to distorted magnetic forces arising from flux weakening control," IEEE Transactions on Magnetics, vol. 49, no. 7, pp. 3929-3932, 2013.

[3] C. H. Lin, "Recurrent wavelet neural network control of a PMSG system based on a PMSM wind turbine emulator," Turkish Journal of Electrical Engineering and Computer Science, vol. 22, no. 4, pp. 795-824, 2014.

[4] B. C. Han, X. Liu, and S. Q. Zheng, "A novel integral 5-DOFs hybrid one permanent magnet ring used for turboexpander," Mathematical Problems in Engineering, vol. 2014, Article ID 162561, 18 pages, 2014.

[5] S. H. Kim, J. W. Shin, and K. Ishiyama, "Magnetic bearings and synchronous magnetic axial coupling for the enhancement of the driving performance of magnetic wireless pumps," IEEE Transactions on Magnetics, vol. 50, no. 1, pp. 1-4, 2014.

[6] Q. Yuan, B. C. Han, and B. T. Dong, "The multiple objective optimization of high-speed rotor supported by magnetic bearing in BLDCM," International Journal of Applied Electromagnetics and Mechanics, vol. 46, no. 3, pp. 663-673, 2014.

[7] W. Y. Zhang and H. Q. Zhu, "Precision modeling method specifically for AC magnetic bearings," IEEE Transactions on Magnetics, vol. 49, no. 11, pp. 5543-5553, 2013.

[8] W. S. Bu, S. H. Huang, and S. M. Wan, "General analytical models of inductance matrices of four-pole bearingless motors with two-pole controlling windings," IEEE Transactions on Magnetics, vol. 45, no. 9, pp. 3316-3321, 2009.
[9] H. Sugimoto, Y. Uemura, A. Chiba, and M. A. Rahman, "Design of homopolar consequent-pole bearingless motor with wide magnetic gap," IEEE Transactions on Magnetics, vol. 49, no. 5, pp. 2315-2318, 2013.

[10] X. D. Sun, L. Chen, and Z. B. Yang, "Overview of bearingless induction motors," Mathematical Problems in Engineering, vol. 2014, Article ID 570161, 10 pages, 2014.

[11] V. F. Victor, F. O. Quintaes, J. S. B. Lopes, L. D. S. Junior, A. S. Lock, and A. O. Salazar, "Analysis and study of a bearingless AC motor type divided winding, based on a conventional squirrel cage induction motor," IEEE Transactions on Magnetics, vol. 48, no. 11, pp. 3571-3574, 2012.

[12] R. Oishi, S. Horima, H. Sugimoto, and A. Chiba, "A novel parallel motor winding structure for bearingless motors," IEEE Transactions on Magnetics, vol. 49, no. 5, pp. 2287-2290, 2013.

[13] W. S. Bu, C. L. Zu, S. J. Wang, and S. H. Huang, "Digital control system design and analyses of a 3-phase bearingless induction motor," Turkish Journal of Electrical Engineering and Computer Science, vol. 22, no. 5, pp. 1193-1209, 2014.

[14] A. Chiba and J. A. Santisteban, "A PWM harmonics elimination method in simultaneous estimation of magnetic field and displacements in bearingless induction motors," IEEE Transactions on Industry Applications, vol. 48, no. 1, pp. 124-131, 2012.

[15] S. Kobayashi, M. Ooshima, and M. N. Uddin, "A radial position control method of bearingless motor based on d-q-axis current control," IEEE Transactions on Industry Applications, vol. 49, no. 4, pp. 1827-1835, 2013.

[16] J. Asama, D. Kanehara, T. Oiwa, and A. Chiba, "Development of a compact centrifugal pump with a two-axis actively positioned consequent-pole bearingless motor," IEEE Transactions on Industry Applications, vol. 50, no. 1, pp. 288-295, 2014.

[17] A. Chiba and J. Asama, "Influence of rotor skew in induction type bearingless motor," IEEE Transactions on Magnetics, vol. 48, no. 11, pp. 4646-4649, 2012.

[18] H. Q. Zhu, Y. Zhou, T. B. Li, and X. X. Liu, "Decoupling control of 5 degrees of freedom bearingless induction motors using $\alpha$ th order inverse system method," Acta Automatica Sinica, vol. 33, no. 3, pp. 273-278, 2007.

[19] X. D. Sun and H. Q. Zhu, "Decoupling control of bearingless induction motors based on neural network inverse system method," Transactions of China Electrotechnical Society, vol. 25, no. 1, pp. 43-49, 2010.

[20] Z. Q. Wang and X. X. Liu, "Nonlinear internal model control for bearingless induction motor based on neural network inversion," Acta Automatica Sinica, vol. 39, no. 4, pp. 433-439, 2013.

[21] Q. Li and X. X. Liu, "Decoupling control of bearingless asynchronous motor based on rotor flux orientation with inverse system theory," Electric Machines \& Control Application, vol. 37, no. 2, pp. 8-12, 2010.

[22] M. Jemli, H. Ben Azza, M. Boussak, and M. Gossa, "Sensorless indirect stator field orientation speed control for single-phase induction motor drive," IEEE Transactions on Power Electronics, vol. 24, no. 6, pp. 1618-1627, 2009.

[23] W. S. Bu, C. X. Lu, C. L. Zu et al., "Research on dynamic decoupling control method of three-phase bearingless induction motor," International Journal of Control and Automation, vol. 7, no. 5, pp. 77-86, 2014. 


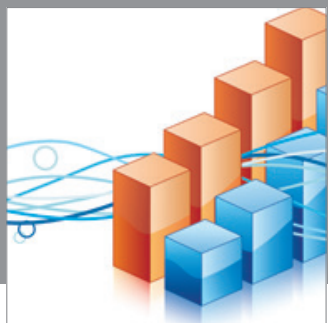

Advances in

Operations Research

mansans

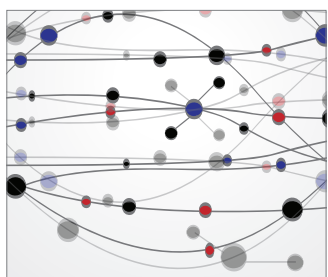

The Scientific World Journal
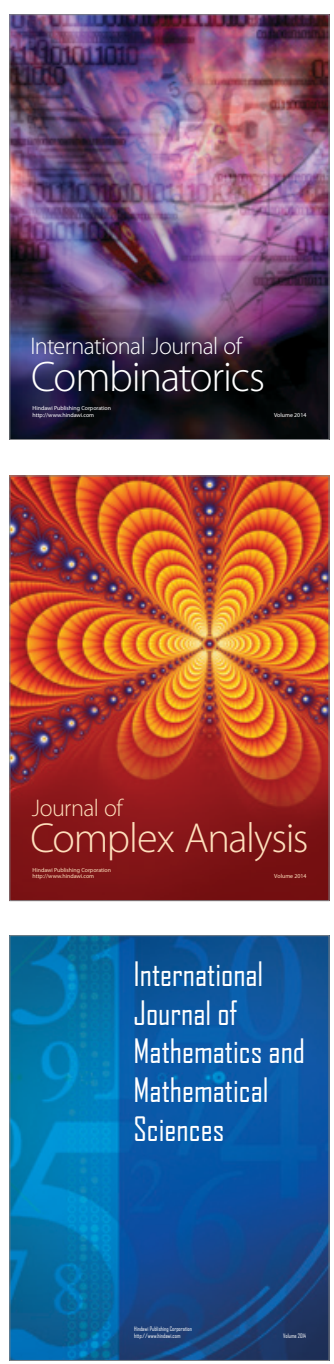
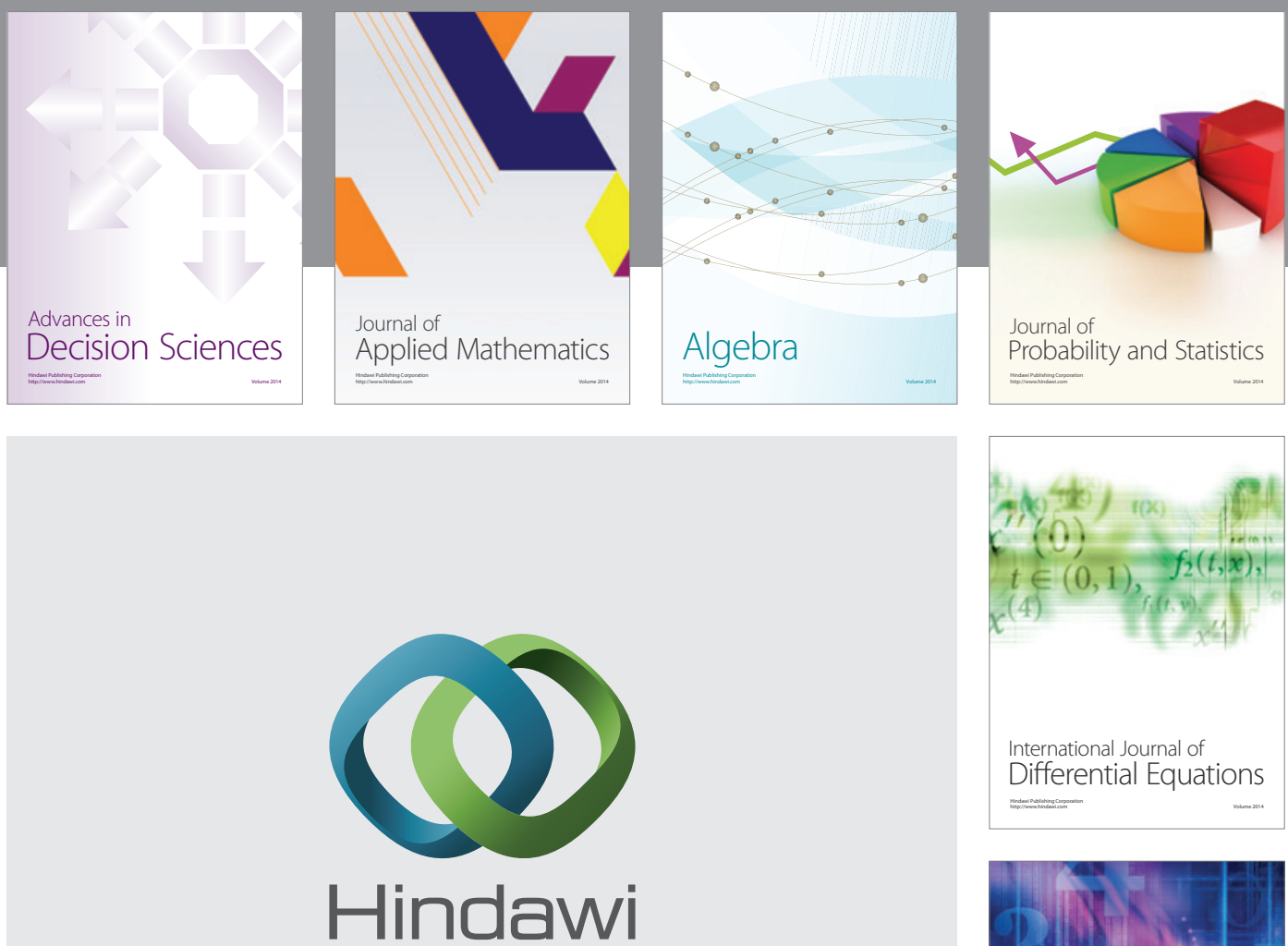

Submit your manuscripts at http://www.hindawi.com
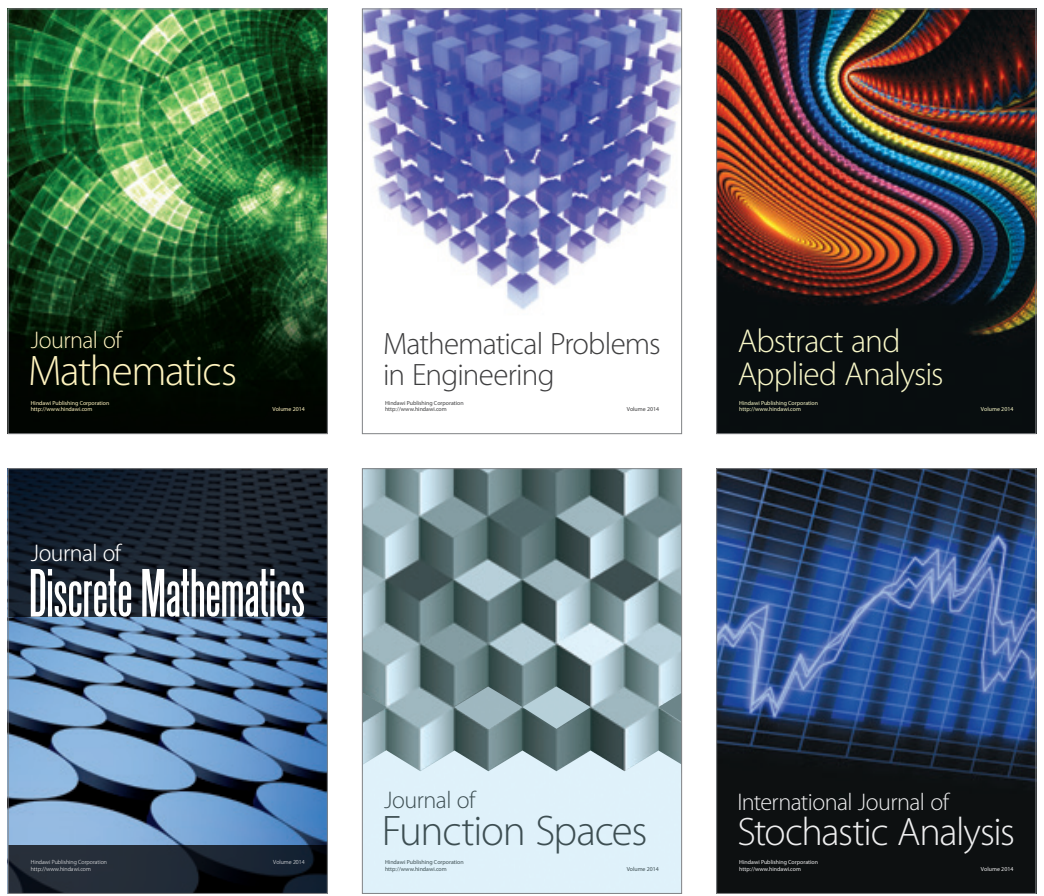

Journal of

Function Spaces

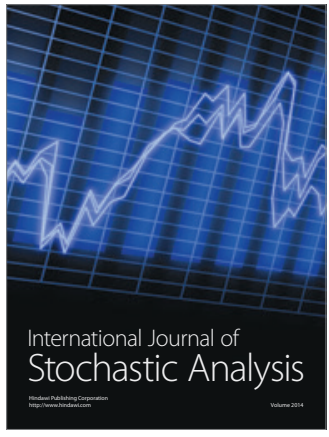

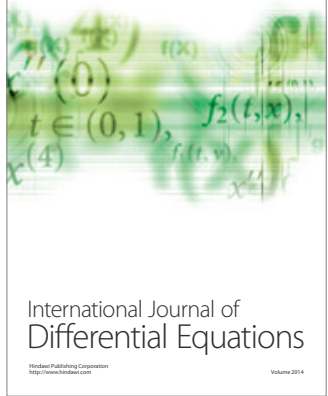
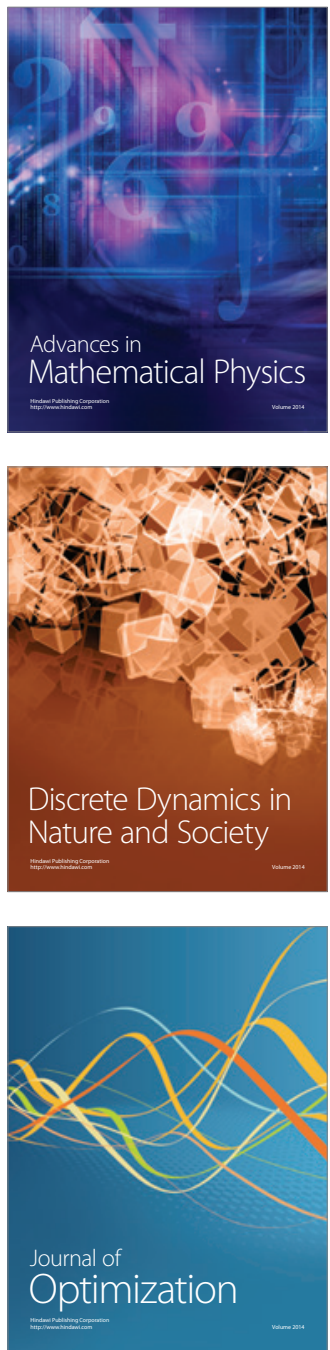